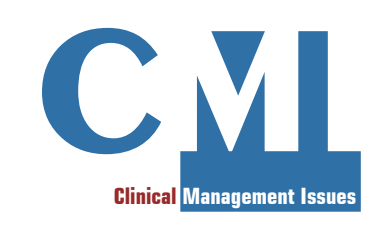

\title{
Acknowledgement to reviewers (June 2014 - March 2015)
}

The editorial staff of Clinical Management Issues (CMI) would like to thank all the reviewers who, with their support and their active cooperation, have contributed to improving the scientific rigor, precision and accuracy of the contents.

- Simonetta Caria

- Piergiorgio Chiriacò

- Claudia Cicala

- Christopher Collins

- Rosario Iannacchero

- Federica Invernizzi

- Alfonso Iudice

- Enrico Lupia

- Roberto Manfredi

- Luca Masotti

- Giuseppe Mulé
- Lucia Palmisano

- Claudio Puoti

- Giulio Radeschi

- Ali Sabzghabaee

- Salvatore Sollima

- Valentina Svicher

- Lidia Usnarska-Zubkiewicz

- André van Zundert

- Mauro Viganò

- Umberto Vitolo

- Jan Wnent 